\title{
Rotigotine's effect on PLM-associated blood pressure elevations in restless legs syndrome
}

\author{
An RCT \\ OPEN
}

Axel Bauer, MD

Werner Cassel, Dipl

Psych

Heike Benes, MD

Karl Kesper, $\mathrm{PhD}$

David Rye, MD, PhD

Domenic Sica, MD

John W. Winkelman,

$\mathrm{MD}, \mathrm{PhD}$

Lars Bauer, MD

Frank Grieger, Dipl Stat

Lars Joeres, $\mathrm{PhD}$

Kimberly Moran, $\mathrm{PhD}$

Erwin Schollmayer, MD,

$\mathrm{PhD}$

John Whitesides, PhD

Hannah C. Carney, PhD

Arthur S. Walters, MD

Wolfgang Oertel, MD

Claudia Trenkwalder, $\mathrm{MD}, \mathrm{PhD}$

On behalf of the SP0977

study investigators

Correspondence to

Dr. Bauer:

axel.bauer@med.uni-muenchen.de

Supplemental data at Neurology.org

\section{ABSTRACT}

Objective: This double-blind, placebo-controlled, interventional trial was conducted to investigate the effects of rotigotine patch on periodic limb movement (PLM)-associated nocturnal systolic blood pressure (SBP) elevations.

Methods: Patients with moderate to severe restless legs syndrome (RLS) were randomized to rotigotine (optimal dose [1-3 mg/24 h]) or placebo. Continuous beat-to-beat blood pressure (BP) assessments were performed during polysomnography at baseline and at the end of 4-week maintenance. Primary outcome was change in number of PLM-associated SBP elevations (defined as slope of linear regression $\geq 2.5 \mathrm{~mm} \mathrm{Hg} /$ beat-to-beat interval over 5 consecutive heartbeats [ $\geq 10 \mathrm{~mm} \mathrm{Hg}]$ ). Additional outcomes were total SBP elevations, PLM-associated and total diastolic BP (DBP) elevations, periodic limb movements index (PLMI), and PLM in sleep arousal index (PLMSAI).

Results: Of 81 randomized patients, 66 (37 rotigotine, 29 placebo) were included in efficacy assessments. PLM-associated SBP elevations were significantly reduced with rotigotine vs placebo (least squares mean treatment difference [95\% confidence interval (CI)] -160.34 [-213.23 to -107.45 ]; $p<0.0001)$. Rotigotine-treated patients also had greater reduction vs placebo in total SBP elevations ( -161.13 [ -264.47 to -57.79 ]; $p=0.0028)$, PLM-associated elevations $(-88.45[-126.12$ to -50.78$] ; p<0.0001)$, and total DBP elevations $(-93.81[-168.45$ to -19.16 ]; $p=0.0146)$, PLMI $(-32.77$ [ -44.73 to -20.80$] ; p<0.0001)$, and PLMSAI $(-7.10$ [-11.93 to -2.26$] ; p=0.0047$ ). Adverse events included nausea (rotigotine 23\%; placebo 8\%), headache (18\% each), nasopharyngitis (18\%; $8 \%)$, and fatigue (13\%; 15\%).

Conclusions: Further investigation is required to determine whether reductions in nocturnal BP elevations observed with rotigotine might modify cardiovascular risk.

Classification of evidence: This study provides Class I evidence that for patients with moderate to severe RLS, rotigotine at optimal dose (1-3 mg/24 h) reduced PLM-associated nocturnal SBP elevations. Neurology ${ }^{\circledR}$ 2016;86:1785-1793

\section{GLOSSARY}

$\mathbf{A E}=$ adverse event; $\mathbf{A N C O V A}=$ analysis of covariance; $\mathbf{A U C}=$ area under the curve; $\mathbf{B P}=$ blood pressure; $\mathbf{C V D}=$ cardiovascular disease; CGI = Clinical Global Impression; $\mathbf{C l}=$ confidence interval; DBP = diastolic blood pressure; ENCORE = Effects of Neupro on Cardiovascular Observations in Patients With RLS; EoM = end of maintenance; $\mathbf{F A S}=$ full analysis set; HR = heart rate; IRLS = International Restless Legs Syndrome Study Group; LS = least squares; PLM = periodic limb movements; PLMSAI = periodic limb movements in sleep arousal index; PLMI = periodic limb movements index; PLMS = periodic limb movements during sleep; PLMW = periodic limb movements during wakefulness preceding sleep onset; QoL = quality of life; $\mathbf{R L S}=$ restless legs syndrome; SBP = systolic blood pressure.

Periodic limb movements (PLM) are present in 85\%-95\% of patients with restless legs syndrome (RLS) ${ }^{1}$ and occur during wakefulness preceding sleep onset (PLMW) as well as during sleep (PLMS). PLMS often coincide with brief cortical arousals from sleep, and both PLMS and

From the Munich University Clinic and DZHK (German Centre for Cardiovascular Research) (A.B.); Philipps Universität Marburg (W.C., K.K., W.O.); Somni Bene Institut für Medizinische Forschung und Schlafmedizin (H.B.), Schwerin; Medical Center (H.B.), Rostock University, Germany; Emory University (D.R.), Atlanta, GA; Virginia Commonwealth University (D.S.), Richmond; Massachusetts General Hospital (J.W.W.), Boston; UCB Pharma (L.B., F.G., L.J., E.S.), Monheim am Rhein, Germany; UCB Pharma (K.M.), Smyrna, GA; UCB Pharma (J.W.), Raleigh, NC; Evidence Scientific Solutions (H.C.C.), Horsham, UK; Vanderbilt University School of Medicine (A.S.W.), Nashville, TN; Hertie Foundation (W.O.), Frankfurt am Main; and Department of Neurosurgery (C.T.), University Medical Center, Göttingen and Paracelsus-Elena-Klinik, Kassel, Germany.

Coinvestigators are listed on the Neurology ${ }^{\circledR}$ Web site at Neurology.org.

Go to Neurology.org for full disclosures. Funding information and disclosures deemed relevant by the authors, if any, are provided at the end of the article. The article processing charge was paid by UCB Pharma.

This is an open access article distributed under the terms of the Creative Commons Attribution-NonCommercial-NoDerivatives License 4.0 (CC BYNC-ND), which permits downloading and sharing the work provided it is properly cited. The work cannot be changed in any way or used commercially. 
PLMW are associated with elevations in systolic and diastolic blood pressure (SBP/DBP) and changes in heart rate (HR) (increase followed by decrease). ${ }^{2-4}$ In patients with RLS, PLMS-associated DBP increases of $10 \mathrm{~mm}$ $\mathrm{Hg}$, SBP increases of $20 \mathrm{~mm} \mathrm{Hg}$, and $\mathrm{HR}$ increases of $\sim 7-10$ beats per minute have been observed. ${ }^{3-5}$ These transient increases in sympathetic activity may convey an elevated risk of cardiovascular disease (CVD). ${ }^{2-4}$

The dopamine receptor agonist rotigotine has demonstrated efficacy in improving sensory symptoms ${ }^{6-8}$ and PLM index (PLMI) ${ }^{9}$ in patients with RLS. As PLM are associated with blood pressure (BP) elevations, ${ }^{2-4}$ their reduction with medication may have beneficial effects upon nocturnal BP profiles. Our study (Effects of Neupro on Cardiovascular Observations in Patients With RLS [SP0977]) (ENCORE) evaluated effects of rotigotine transdermal system on nocturnal SBP elevations associated with PLM in patients with moderate to severe RLS.

METHODS Standard protocol approvals, registrations, and patient consents. This study was conducted in accordance with good clinical practice and the Declaration of Helsinki. The protocol and amendments were reviewed by a national, regional, or independent ethics committee or institutional review board. All patients provided written informed consent. The study was registered with ClinicalTrials.gov (NCT01455012).

Patients. This randomized, double-blind, placebo-controlled, multicenter sleep laboratory study enrolled patients aged 18-75 years from 9 sites in Germany. Eligibility criteria related to RLS severity were assessed at the screening visit. These included an RLS Diagnostic Index ${ }^{10}$ score $\geq 11$, International Restless Legs Syndrome Study Group rating scale (IRLS) ${ }^{11}$ score $\geq 15$ (at least moderate severity), Clinical Global Impression (CGI) scale severity score ${ }^{12} \geq 4$ (at least marked severity), PLMI $\geq 15 /$ hour (documented on a single baseline night of polysomnography), and a favorable initial response to previous dopaminergic RLS treatment if pretreated (prior augmentation was not explicitly considered as an exclusion criterion). Patients were excluded if they had an apnea-hypopnea index of $\geq 15$ /hour (local polysomnographic evaluation), a history of sleep disturbances (sleep apnea syndrome [including obstructive sleep apnea], narcolepsy, sleep attacks/sudden sleep onset), uncontrolled hypertension (according to the judgment of the investigator), or a myocardial infarction within the previous 12 months (additional criteria in appendix e-1: Supplemental methods on the Neurology ${ }^{\circledR}$ Web site at Neurology.org). Prior stroke was not an exclusion criterion; however, none of the enrolled patients had a history of stroke. Patients receiving antihypertensives were required to be on a stable dose for at least 4 weeks prior to baseline, with reasonably controlled hypertension (as determined by the investigator), and to continue with their medication at this dose for the duration of the study. Eligible patients entered a washout period (termed screening period in the protocol) of 1-14 days. The time period was dependent on the individual patient's preexisting medications (e.g., any existing RLS therapies/prohibited concomitant medications). Use of any dopamine agonist within 14 days prior to baseline, or levodopa within 7 days prior to baseline, was prohibited.

Study design. Patients were randomized 1:1 to rotigotine or placebo using an interactive voice response system. Strata were defined by antihypertensive comedication use at baseline (concomitant antihypertensive use vs no antihypertensive use). Study medication was administered via a transdermal patch, which was replaced every 24 hours (appendix e-1: Supplemental methods). Patients were uptitrated to their optimal dose $(1-3 \mathrm{mg} / 24 \mathrm{~h}$ rotigotine or placebo) from a starting dose of $1 \mathrm{mg} / 24 \mathrm{~h}$ $(1 \mathrm{mg} / 24 \mathrm{~h}$ increments at 7-day intervals; maximum titration: 21 [+3 days]). Upon reaching optimal/maximal dose, patients entered a 4-week maintenance period. No further dose adjustments were permitted; patients requiring backtitration were withdrawn. Maintenance was followed by a 1 -week taper period and 28-day safety follow-up.

Polysomnography. Polysomnography was performed at the individual investigation sites on 2 consecutive nights at baseline, and again on 2 consecutive nights at end of maintenance (EoM). Each center used the same procedure in terms of channel montage setup and documentation, and a time in bed (first "lights off" to last "lights on") of 8 hours was observed as precisely as possible. Assessments included continuous noninvasive beat-tobeat BP recordings (Portapres Model-2 system, Finapres Medical Systems, Amsterdam, the Netherlands), 6-lead EKG (Frank leads configuration), EEG, electro-oculogram, chin EMG, and bilateral anterior tibialis surface EMG

Recordings were exported into European data format, ${ }^{13} \mathrm{en}-$ crypted, and transferred to a central reader (Sleep Disorders Center, University of Marburg, Germany) for standardized assessment/evaluation. Visual scoring of sleep stages, arousals (sudden transient EEG activations), and respiratory events was carried out by a single experienced scorer according to American Academy of Sleep Medicine guidelines. ${ }^{14}$ PLM were defined as 4 or more consecutive limb movements of $0.5-10$ seconds in duration, with individual movements separated by an interval of 5-90 seconds. ${ }^{15}$ PLMS and PLMW were scored according to World Association of Sleep Medicine standards. ${ }^{15}$ BP recordings were reviewed and corrected for artifacts by an experienced technician.

Analyses of BP and HR elevations. Full details of the methodology used to evaluate associations between PLM and BP/HR elevations have been reported previously. ${ }^{16}$ Figure e-1 shows an example polysomnogram. Analyses for identification of SBP, DBP, and HR elevations started with the period of the first 5 consecutive heartbeats available after lights out. SBP, DBP, and HR elevations were defined as a slope of linear regression $\geq 2.5$ over 5 consecutive heartbeats, equivalent to a SBP/DBP increase of $\geq 2.5 \mathrm{~mm} \mathrm{Hg} /$ beat-to-beat interval (equivalent to $\geq 10 \mathrm{~mm}$ $\mathrm{Hg}$ ) or a HR increase of 2.5 beats per minute per heartbeat. The 20 -second period ranging from 7 seconds prior to elevation onset to 13 seconds after elevation onset was defined as the elevation segment. If an elevation was found, the procedure for identifying further elevations continued with the first 5 heartbeats following the elevation segment. If no elevation was detected, the 5-heartbeat window moved forward by a single heartbeat, and the procedure was repeated. A BP/HR elevation was considered to be associated with a PLM if the PLM started within the first 7 seconds of the 20-second elevation segment.

Outcome measures. Primary outcome was mean change from baseline in number of PLM-associated nocturnal SBP elevations. 
Additional efficacy outcomes included mean changes in the numbers of total nocturnal SBP elevations, PLM-associated nocturnal DBP elevations, total DBP elevations, PLM-associated HR elevations, and total HR elevations. SBP and DBP elevation indices (number of elevations/hour in bed), mean nocturnal SBP and DBP, and PLMI (number of PLM/hours in bed) were also assessed. Post hoc evaluations included numbers of SBP and DBP elevations not associated with PLM, area under the curve (AUC; $\mathrm{mm} \mathrm{Hg} \times$ seconds) for SBP and DBP elevations with/without PLM, the percentages of PLM occurring with SBP/DBP elevations, periodic limb movement in sleep arousal index (PLMSAI; PLMS associated with arousal/total sleeping time), and numbers of PLMS occurring with/without arousals. We also performed a post hoc evaluation of PLM indices and SBP/DBP/HR elevation indices per sleep stage (number of events/hours in sleep stage).

RLS symptom severity was evaluated using IRLS, ${ }^{11}$ RLS quality of life (RLS-QoL), ${ }^{17}$ CGI-1 (severity of illness), CGI-2 (change of condition), CGI-3 (therapeutic efficacy), ${ }^{12}$ and RLS-6 scales. ${ }^{18}$ Safety outcomes included incidence and severity of adverse events (AEs), vital signs, physical and neurologic assessments, and CGI-4 (side effects).

Statistical analyses. Efficacy analyses were performed for the full analysis set (FAS; all patients with a baseline and postbaseline measurement for the primary outcome). Randomization of $72 \mathrm{pa}-$ tients was planned, with the goal of obtaining complete data from 60 patients. For the primary outcome, an analysis of covariance (ANCOVA) was performed for change from baseline to EoM with a fixed effect for treatment, an adjustment for the fixed effect of baseline antihypertensive use, and a covariate for the baseline number of PLM-associated nocturnal SBP elevations. Treatment effects were estimated on the basis of the least squares (LS) mean of the difference and its $95 \%$ confidence interval (CI). Analysis of the primary outcome was performed using a 2-sided $\alpha$ level of $5 \%$. The sample size calculation was based on the precision of the estimation. All secondary analyses were exploratory; ANCOVAs were performed with a fixed effect for treatment, an adjustment for the fixed effect of baseline hypertensive use, and a covariate for baseline of the respective parameter. CGI, RLS-6, and safety outcomes were analyzed descriptively. All patients receiving at least one dose of study medication were included in safety analyses.

Classification of evidence. The primary research question was whether rotigotine could reduce the nocturnal SBP elevations associated with PLM in patients with moderate to severe RLS. This study provides Class I evidence that for patients with moderate to severe RLS, rotigotine at optimal dose (1-3 mg/24 h) reduced PLM-associated nocturnal SBP elevations.

RESULTS Patients. Of 81 randomized patients, 80 received study medication and 67 completed the 4-week maintenance period (figure 1). In total, 66 patients were included in the FAS (figure 1; table 1); one patient on placebo was excluded due to a nonreadable baseline polysomnographic recording. Patients had a high PLMI at baseline (table 2) and severe RLS as indicated by mean IRLS scores (26.6 \pm 4.6; $27.1 \pm 5.1$ ) (table e-1). Of 15 patients who discontinued prematurely, one did not receive study medication, 10 withdrew during titration, 3 withdrew during maintenance, and 1 withdrew after completion of the maintenance period. AEs were the most common reason for premature discontinuation among rotigotinetreated patients, whereas the majority of discontinuations

Figure 1 Study flow chart

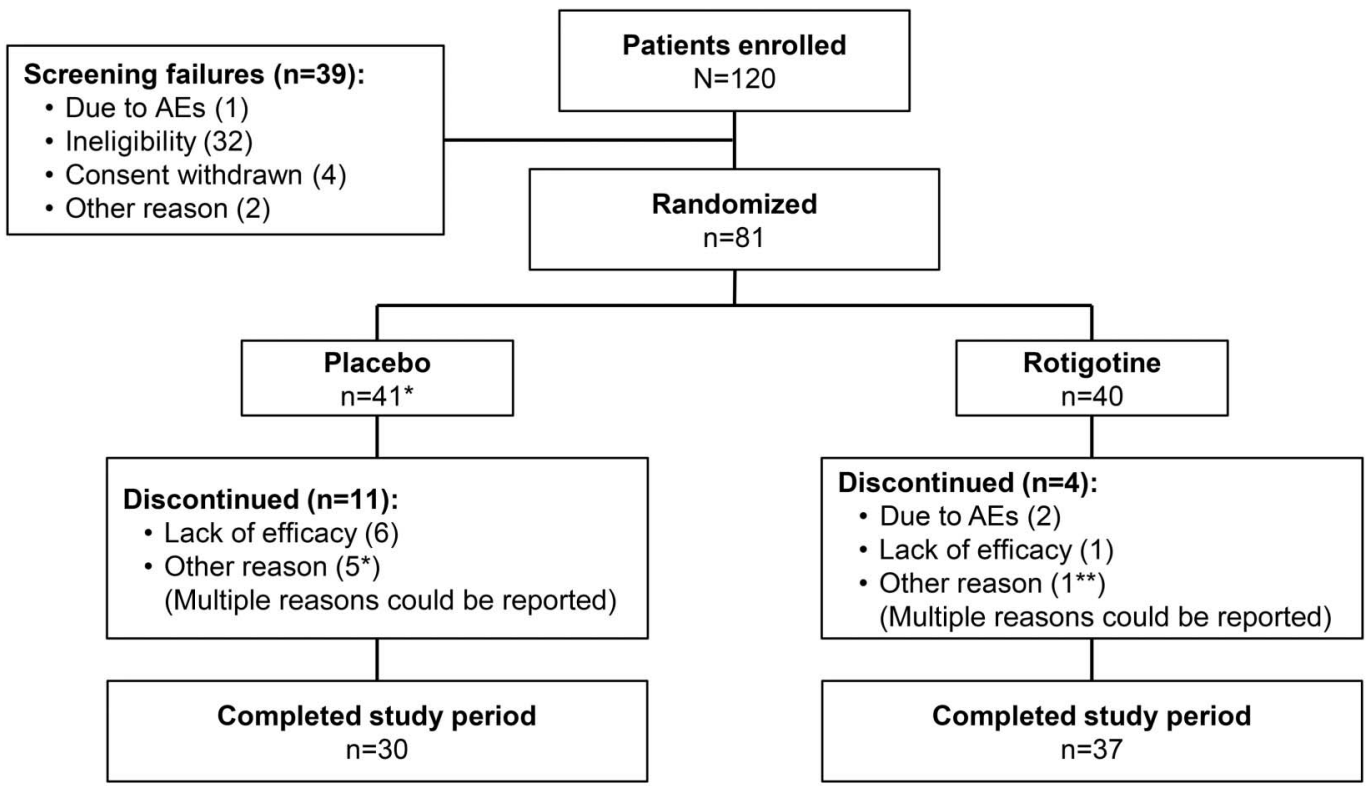

SS: $n=80$

FAS: $n=66$

AEs $=$ adverse events; FAS $=$ full analysis set; $S S=$ safety set. *One patient did not receive study medication. $* *$ Patient discontinued after completing the maintenance period. 


\begin{tabular}{|c|c|c|}
\hline Baseline characteristics & & \\
\hline & Placebo & Rotigotine \\
\hline Safety set, $\mathrm{n}$ & 40 & 40 \\
\hline Age, $y$, mean $\pm S D$ & $57.4 \pm 9.1$ & $57.8 \pm 11.2$ \\
\hline Female, n (\%) & $26(65)$ & $25(63)$ \\
\hline Caucasian, n (\%) & $40(100)$ & 39 (98) \\
\hline $\mathrm{BMI}, \mathrm{kg} / \mathrm{m}^{2}$, mean $\pm \mathrm{SD}$ & $27.8 \pm 3.8$ & $27.2 \pm 3.9$ \\
\hline Duration of RLS, y, median (range) ${ }^{a}$ & $8.4(1.1-44.6)$ & $9.6(0.8-54.6)$ \\
\hline Prior RLS therapy, n (\%) & $31(78)$ & $30(75)$ \\
\hline Full analysis set & 29 & 37 \\
\hline Antihypertensive use at baseline, $\mathrm{n}(\%)$ & $13(45)$ & $15(41)$ \\
\hline
\end{tabular}

Abbreviations: $\mathrm{BMI}=$ body mass index; RLS = restless legs syndrome. a Time since onset of first RLS symptoms.
SBP, DBP, and HR elevations per sleep stage indicated these events were most frequent during N1 sleep (table e-3), which also happened to be the sleep stage that patients spent the most time in (table e-2; appendix e-1: Supplemental results).

Additional outcomes. Overall severity of RLS symptoms improved with rotigotine vs placebo (IRLS; LS mean treatment difference $[95 \% \mathrm{CI}]-6.53[-10.25$ to -2.80$] ; p=0.0009)$, as did patient quality of life (RLS-QoL; -6.32 [ -11.90 to -0.73$], p=0.0273$ ) (appendix e-1: Supplemental results).

Adverse events. In total, 26 (65\%) patients on rotigotine and $24(60 \%)$ placebo patients reported an $\mathrm{AE}$ (table 3). The majority of AEs were mild to moderate in intensity; 4 patients experienced a severe $\mathrm{AE}$, of whom 3 were receiving rotigotine. No serious $\mathrm{AEs}$ were reported. Two rotigotine-treated patients withdrew due to AEs; one withdrew after experiencing 5 moderate AEs over a 7-day period (nausea, cardiac circulatory disturbance, fatigue, headache, and tachycardia), and one withdrew due to severe allergic dermatitis. In addition, 4 patients had a dose change following an AE. Two rotigotine-treated patients had dose increases following AEs of somnolence (1 patient) and dizziness (1 patient), one rotigotine-treated patient had a dose reduction due to dizziness, and one placebo patient had a dose reduction due to headache. There were no clinically relevant changes in vital signs, physical or neurologic examinations, or ECGs.

DISCUSSION Rotigotine significantly reduced the total number of nocturnal SBP elevations associated with PLM in patients with RLS. These results were supported by secondary outcomes that showed positive effects of rotigotine on SBP and DBP elevations (with/without antihypertensives), PLMI, and PLMSAI. If PLM-related BP elevations are a risk factor for arterial hypertension and CVD, their reduction with medication may lead to attenuated risks of CVD. There is substantial evidence that increased short-term (minutes-to-hours) and longterm (days-to-years) BP variability is linked to cardiovascular risk. ${ }^{19}$ Two studies (one in patients with essential hypertension ${ }^{20}$ and one in untreated patients referred to a hypertension clinic $^{21}$ ) quantified BP variability on a beat-to-beat basis and showed a link between increased BP variability and end-organ damage. ${ }^{20,21}$

RLS is associated with a nondipping pattern of nocturnal BP, an independent predictor of cardiovascular risk, ${ }^{22}$ and prevalence of PLMS has been correlated with severity of daytime hypertension in hypertensive patients. ${ }^{23}$ Among patients with RLS, the likelihood of hypertension has been shown to increase with PLMS severity. ${ }^{24}$ However, associations 


\begin{tabular}{|c|c|c|c|c|c|}
\hline \multirow[t]{3}{*}{ Polysomnographic assessments } & ysis set) & & & & \multirow[b]{3}{*}{ LS mean treatment difference $(95 \% \mathrm{Cl}), \mathrm{p}$ value } \\
\hline & \multicolumn{2}{|c|}{ Baseline, mean \pm SD } & \multicolumn{2}{|c|}{ Change from baseline, mean \pm SD } & \\
\hline & Placebo $(n=29)$ & Rotigotine $(n=37)$ & Placebo $(n=29)$ & Rotigotine $(n=37)$ & \\
\hline \multicolumn{6}{|l|}{ SBP assessed during time in bed ${ }^{a}$} \\
\hline Total PLM-associated SBP elevations & $293.2 \pm 218.9$ & $304.3 \pm 273.5$ & $-73.1 \pm 189.3$ & $-240.1 \pm 237.1$ & $-160.34(-213.23$ to -107.45$),<0.0001$ \\
\hline Patients on antihypertensives ${ }^{b}$ & $265.2 \pm 219.6$ & $397.9 \pm 374.9$ & $-90.5 \pm 164.5$ & $-315.9 \pm 315.8$ & $-127.78(-221.59$ to -33.96$), 0.0096$ \\
\hline Patients without antihypertensives $^{c}$ & $316.0 \pm 222.7$ & $240.5 \pm 154.9$ & $-58.9 \pm 211.6$ & $-188.5 \pm 151.7$ & $-190.60(-257.71$ to -123.50$),<0.0001$ \\
\hline Total SBP elevations & $775.5 \pm 248.6$ & $793.1 \pm 305.7$ & $-34.3 \pm 243.4$ & $-199.8 \pm 262.8$ & $-161.13(-264.47$ to -57.79$), 0.0028$ \\
\hline Patients on antihypertensives ${ }^{b}$ & $797.8 \pm 256.1$ & $883.1 \pm 332.9$ & $-82.4 \pm 205.1$ & $-311.4 \pm 249.9$ & $-196.00(-356.00$ to -36.01$), 0.0184$ \\
\hline Patients without antihypertensives $^{c}$ & $757.4 \pm 249.3$ & $731.7 \pm 276.8$ & $4.8 \pm 270.6$ & $-123.7 \pm 248.6$ & -142.73 ( -286.09 to 0.62$), 0.0509$ \\
\hline Total non-PLM-associated SBP elevations & $482.3 \pm 178.6$ & $488.8 \pm 244.7$ & $38.8 \pm 136.4$ & $40.4 \pm 207.1$ & 1.16 (-83.55 to 85.87$), 0.9783$ \\
\hline SBP elevation index, elevations/time in bed, $\mathrm{h}$ & $102.9 \pm 33.1$ & $105.5 \pm 40.6$ & $-6.9 \pm 32.0$ & $-25.9 \pm 34.3$ & $-18.23(-31.92$ to -4.53$), 0.0099$ \\
\hline AUC for SBP elevations, $\mathrm{mm} \mathrm{Hg} \times \mathbf{s}$ & $179.7 \pm 41.6$ & $180.1 \pm 51.4$ & $-7.6 \pm 30.0$ & $-10.1 \pm 37.4$ & -2.22 (-16.85 to 12.42$), 0.7630$ \\
\hline AUC for PLM-associated SBP elevations & $186.0 \pm 62.2$ & $185.3 \pm 56.1$ & $-9.3 \pm 57.0$ & $-20.5 \pm 65.5$ & $-10.67(-36.68$ to 15.34$), 0.4154$ \\
\hline AUC for non-PLM-associated SBP elevations & $178.6 \pm 43.6$ & $180.1 \pm 50.5$ & $-6.8 \pm 32.6$ & $-8.4 \pm 36.5$ & $-1.10(-16.21$ to 14.01$), 0.8844$ \\
\hline Nocturnal SBP, mm Hg & $116.1 \pm 18.8$ & $116.0 \pm 22.7$ & $2.7 \pm 16.1$ & $-2.1 \pm 15.8$ & $-5.08(-11.79$ to 1.63$), 0.1351$ \\
\hline \multicolumn{6}{|l|}{ DBP assessed during time in bed ${ }^{a}$} \\
\hline Total PLM-associated DBP elevations & $170.4 \pm 161.7$ & $148.3 \pm 174.7$ & $-46.1 \pm 121.5$ & $-118.4 \pm 151.7$ & $-88.45(-126.12$ to -50.78$),<0.0001$ \\
\hline Patients on antihypertensives ${ }^{b}$ & $163.6 \pm 175.9$ & $194.3 \pm 237.9$ & $-67.4 \pm 83.6$ & $-153.7 \pm 201.7$ & $-66.09(-126.38$ to -5.80$), 0.0330$ \\
\hline Patients without antihypertensives $^{c}$ & $175.9 \pm 154.8$ & $116.9 \pm 109.8$ & $-28.8 \pm 145.8$ & $-94.3 \pm 104.0$ & $-110.03(-161.40$ to -58.66$), 0.0001$ \\
\hline Total DBP elevations & $361.7 \pm 223.8$ & $342.6 \pm 267.7$ & $-61.1 \pm 175.5$ & $-141.7 \pm 234.0$ & $-93.81(-168.45$ to -19.16$), 0.0146$ \\
\hline Patients on antihypertensives ${ }^{b}$ & $387.7 \pm 269.7$ & $400.7 \pm 315.6$ & $-111.8 \pm 153.6$ & $-197.5 \pm 215.1$ & -79.34 (-179.94 to 21.09$), 0.1162$ \\
\hline Patients without antihypertensives $^{c}$ & $340.6 \pm 185.2$ & $303.0 \pm 228.9$ & $-19.8 \pm 186.0$ & $-103.7 \pm 243.4$ & -110.94 ( -220.06 to -1.82$), 0.0465$ \\
\hline Total non-PLM-associated DBP elevations & $191.3 \pm 120.6$ & $194.3 \pm 154.6$ & $-15.0 \pm 92.4$ & $-23.3 \pm 166.6$ & -7.86 (-67.03 to 51.32$), 0.7916$ \\
\hline DBP elevation index, elevations/time in bed, $h$ & $48.3 \pm 30.4$ & $45.7 \pm 36.1$ & $-9.2 \pm 23.5$ & $-18.7 \pm 31.1$ & $-11.19(-21.24$ to -1.13$), 0.0298$ \\
\hline AUC for DBP elevations, $\mathrm{mm} \mathrm{Hg} \times \mathbf{s}$ & $50.2 \pm 16.0$ & $52.1 \pm 17.1$ & $2.1 \pm 11.6$ & $-8.8 \pm 24.7$ & $-9.46(-17.71$ to -1.21$), 0.0253$ \\
\hline AUC for PLM-associated DBP elevations & $45.7 \pm 29.4$ & $46.8 \pm 22.8$ & $2.0 \pm 26.5$ & $-16.7 \pm 31.9$ & $-17.46(-29.80$ to -5.13$), 0.0063$ \\
\hline AUC for non-PLM-associated DBP elevations & $54.5 \pm 13.8$ & $55.9 \pm 17.2$ & $2.5 \pm 11.5$ & $-11.5 \pm 25.5$ & $-12.98(-21.74$ to -4.23$), 0.0043$ \\
\hline Nocturnal DBP, mm Hg & $58.7 \pm 12.9$ & $58.8 \pm 12.5$ & $2.4 \pm 11.2$ & $-1.4 \pm 10.0$ & $-3.98(-8.14$ to 0.18$), 0.0602$ \\
\hline \multicolumn{6}{|l|}{ HR assessed during time in bed ${ }^{a}$} \\
\hline Total PLM-associated HR elevations & $110.1 \pm 108.8$ & $98.1 \pm 116.8$ & $-38.9 \pm 80.3$ & $-79.7 \pm 101.5$ & $-49.58(-73.59$ to -25.57$), 0.0001$ \\
\hline Total HR elevations & $421.7 \pm 340.1$ & $362.4 \pm 353.4$ & $-66.2 \pm 223.8$ & $-143.0 \pm 267.0$ & $-94.53(-210.34$ to 21.29$), 0.1079$ \\
\hline HR elevation index, elevations/time in bed, $h$ & $55.8 \pm 43.9$ & $47.9 \pm 47.0$ & $-9.5 \pm 29.2$ & $-18.3 \pm 35.6$ & $-10.87(-26.49$ to 4.74$), 0.1690$ \\
\hline
\end{tabular}




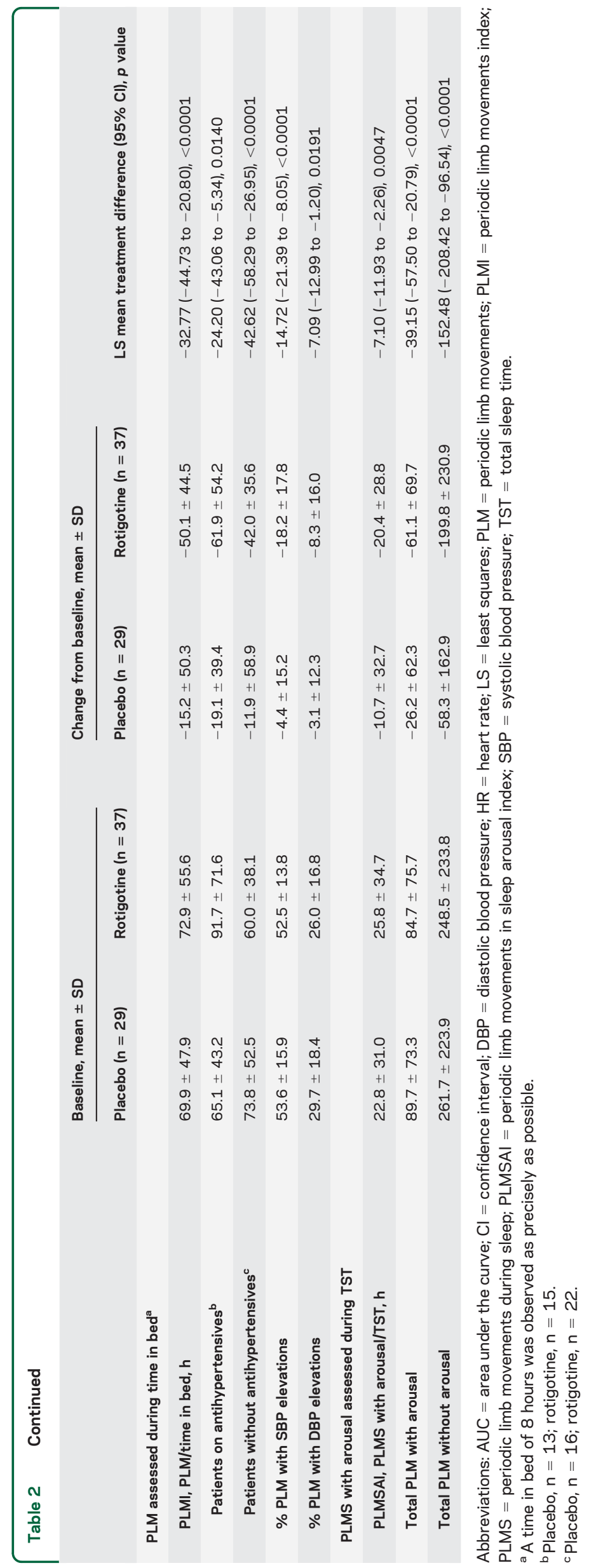

among RLS, hypertension, and CVD remain controversial, and causality has not been established..$^{25,26}$

As PLM occur in synchrony with BP/HR elevations and it is well-established that D2-D3 dopamine agonists reduce PLM in patients with RLS, the most parsimonious explanation for the effect of rotigotine on $\mathrm{BP} / \mathrm{HR}$ elevations is that they are a consequence of the reduction in number of PLM. By eliminating the PLM, dopamine agonists may, by default, reduce or eliminate the concurrent autonomic activation. This is supported by observed reductions in total $\mathrm{BP} / \mathrm{HR}$ elevations with rotigotine, although other mechanisms such as reduced sympathetic drive may contribute to this effect. The role of dopamine in $\mathrm{BP}$ regulation is well-documented, ${ }^{27}$ and dopamine agonists have been shown to lower BP through reductions in peripheral venous and arterial tone. ${ }^{28}$ Consistent with these effects, our study showed a slight decrease in mean SBP and DBP with rotigotine.

It is difficult to ascertain whether effects of rotigotine on BP elevations are mediated principally by a reduction of PLM or are alternate direct effects on BP. Comparable reductions in total BP elevations and in PLM-associated BP elevations suggest the effects of rotigotine were primarily due to elimination of PLM resulting in elimination of the associated BP elevations. A substantial number of BP elevations occurred in the absence of PLM, and remained following rotigotine treatment. The clinical relevance of these non-PLMassociated BP elevations is unknown. No relevant treatment effects were observed for AUC of SBP elevations with/without PLM. In contrast, the AUCs of both PLM-associated and non-PLM-associated DBP elevations were reduced with rotigotine. It appears that the AUCs of BP elevations occurring with/without PLM respond similarly to treatment, but responses differ between SBP and DBP elevations. These interesting findings indicate an additional peripheral mechanism of action and warrant further research.

PLM-associated BP/HR elevations are present in healthy individuals with no sleep concerns, but are of greater magnitude in patients with RLS. ${ }^{2}$ Significant $\mathrm{BP} / \mathrm{HR}$ increases do not occur after voluntary movements, indicating that PLM-associated autonomic activations are not solely due to the leg movements themselves. ${ }^{3}$ Furthermore, BP elevations are more significant when PLMS are accompanied by EEG arousals than without. ${ }^{4}$ One study showed that dopaminergic therapy may suppress PLMS in patients with RLS without affecting EEG arousals. ${ }^{29}$ In theory, EEG arousals may continue to produce $\mathrm{BP} / \mathrm{HR}$ elevations in the absence of PLMS. However, this was not supported by our data: rotigotine reduced both PLM-associated EEG arousals and BP/HR elevations. In addition, a small-scale study indicated that the increased PLMrelated HR response observed in patients with RLS is 


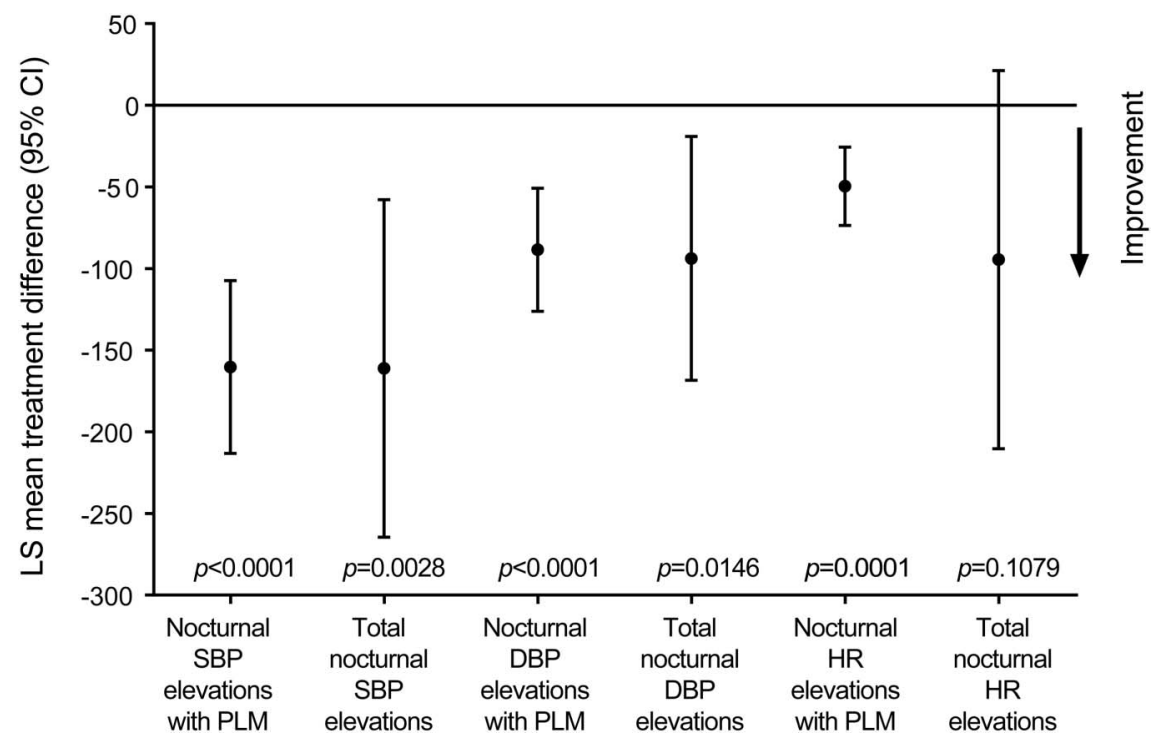

Rotigotine-placebo treatment difference for change from baseline to the end of the 4-week maintenance period. $\mathrm{Cl}=$ confidence interval; DBP = diastolic blood pressure; $L S=$ least squares; PLM = periodic leg movements; $\mathrm{SBP}=$ systolic blood pressure.

normalized by dopaminergic agents. ${ }^{30}$ These observations could point to subcortical, spinal, or peripheral actions of dopamine agonists in reducing sympathetic tone. To further tease apart the individual contributions of PLM, EEG arousals, and BP elevations, future studies would be most informative if they included a third arm in which patients received a medication such as clonazepam, which may improve the sensory symptoms of RLS and reduce EEG arousals, but may have less effect on PLMS. ${ }^{29}$

A potential study limitation was the use of the Portapres system, which tracks dynamic changes of $\mathrm{BP}$ in the short term, but is not intended to measure absolute values such as baseline BP. Periodic inflations of the finger cuffs may have influenced sleep and artifact corrections were required, though of course these limitations apply to both treatment groups. We derived a unique definition to define transient nocturnal BP and HR elevations ${ }^{16}$ because no standardized

\section{Table 3 Adverse events with an incidence of $\geq 10 \%$ in either treatment group (safety set)}

\begin{tabular}{lll}
$\begin{array}{l}\text { Preferred term } \\
\text { (MedDRA version 9.1) }\end{array}$ & $\begin{array}{l}\text { Placebo } \\
(\mathbf{n}=40), \mathrm{n}(\%)\end{array}$ & $\begin{array}{l}\text { Rotigotine } \\
(\mathrm{n}=40), \mathrm{n}(\%)\end{array}$ \\
\hline Headache & $7(18)$ & $7(18)$ \\
Nausea & $3(8)$ & $9(23)$ \\
Fatigue & $6(15)$ & $5(13)$ \\
Nasopharyngitis & $3(8)$ & $7(18)$ \\
Somnolence & $4(10)$ & $4(10)$ \\
Dizziness & $1(3)$ & $4(10)$ \\
Pruritus & $1(3)$ & $4(10)$
\end{tabular}

definition exists. Our approach was consistent with the characteristic magnitude and temporal pattern of PLMassociated BP and HR elevations, and could potentially provide a tool for further research. Among patients taking antihypertensives, time of medication intake may have influenced nocturnal BP. However, sensitivity analyses of the primary outcome showed rotigotine had similar effects among subgroups of patients with and without antihypertensive medications. A larger patient sample would be needed in order to fully explore the effects of rotigotine in patients with specific cardiovascular risk factors. Our study raises further questions regarding the effects of dopamine agonists on $\mathrm{BP}$ in both normotensive and hypertensive patients with RLS, and potential mechanisms of action. Assessment of daytime BP fluctuations and BP dipping in patients receiving dopaminergic therapy for RLS would be interesting. This was not addressed in our study due to the burden of technical investigations for each patient. Finally, as our study focused on effects of rotigotine on PLM-associated BP elevations in patients with RLS, we did not include a non-RLS comparison arm. Future studies should use this method to assess BP elevations in RLS and non-RLS populations.

Further investigation is required to determine whether the reductions in BP and HR elevations observed with the rotigotine transdermal system might translate into a reduction in cardiovascular risk among patients with RLS.

\section{AUTHOR CONTRIBUTIONS}

A. Bauer was involved in drafting/revising the manuscript for content, study concept or design, and analysis or interpretation of data. W. Cassel was involved in drafting/revising the manuscript for content, study 
concept or design, and analysis or interpretation of data. H. Benes was involved in drafting/revising the manuscript for content, study concept or design, analysis or interpretation of data, and acquisition of data. $\mathrm{K}$. Kesper was involved in study concept or design and analysis or interpretation of data. D. Rye was involved in drafting/revising the manuscript for content, study concept or design, and analysis or interpretation of data. D. Sica was involved in drafting/revising the manuscript for content, study concept or design, and analysis or interpretation of data. J. Winkelman was involved in drafting/revising the manuscript for content, study concept or design, and analysis or interpretation of data. L. Bauer was involved in study concept or design and analysis or interpretation of the data. F. Grieger was involved in drafting/revising the manuscript for content, study concept or design, analysis or interpretation of data, and statistical analysis. L. Joeres was involved in drafting/revising the manuscript for content, study concept or design, and analysis or interpretation of data. K. Moran was involved in study concept or design, analysis or interpretation of data, and obtaining funding. E. Schollmayer was involved in drafting/revising the manuscript for content, study concept or design, analysis or interpretation of data, acquisition of data, and statistical analysis. J. Whitesides was involved in drafting/revising the manuscript for content, study concept or design, analysis or interpretation of data, study supervision or coordination, and obtaining funding. H. Carney was involved in drafting/revising the manuscript for content. A. Walters was involved in drafting/revising the manuscript for content, study concept or design, and analysis or interpretation of data. W. Oertel was involved in drafting/revising the manuscript for content, study concept or design, analysis or interpretation of data, acquisition of data, obtaining funding, and study supervision or coordination. C. Trenkwalder was involved in drafting/revising the manuscript for content, study concept or design, analysis or interpretation of data, acquisition of data, and study supervision or coordination.

\section{ACKNOWLEDGMENT}

The authors thank Jesse Fishman (UCB Inc, Smyrna, GA) for publication coordination, the patients, and the investigators and their teams who contributed to this study.

\section{STUDY FUNDING}

Supported by UCB, Monheim am Rhein, Germany. Clinical Trial Registration: http://www.clinicaltrials.gov/. Unique identifier: NCT01455012.

\section{DISCLOSURE}

A. Bauer has served as a consultant and advisor to UCB Pharma. W. Cassel has received consulting fees from UCB Pharma. H. Benes has received advisory board honoraria from UCB Pharma and Mundipharma. K. Kesper reports no disclosures relevant to the manuscript. D. Rye has served as a consultant/advisor to UCB Pharma, Jazz Pharmaceuticals, and XenoPort Inc. He has not received industry/government/state research funding. His research is presently funded by individual patient contributions. D. Sica has attended an advisory board for UCB Pharma. J. Winkelman has served as a consultant for UCB Pharma and XenoPort Inc. and received research support from UCB Pharma, GlaxoSmithKline, Impax Pharmaceuticals, and National Institute of Mental Health. L. Bauer is an employee of UCB Pharma. F. Grieger is an employee of UCB Pharma. L. Joeres is an employee of UCB Pharma. K. Moran is an employee of UCB Pharma and receives stock options. E. Schollmayer is an employee of UCB Pharma. J. Whitesides is an employee of UCB Pharma. H. Carney provided writing and editorial assistance toward the development of the manuscript, which was contracted by UCB Pharma. A. Walters has received consulting fees and research funding from UCB Pharma and Mundipharma. W. Oertel has served as a consultant for Novartis and UCB Pharma; on advisory boards for Boehringer Ingelheim, Merck, Sharp \& Dohme, Medtronic, Mundipharma, Novartis, UCB Pharma, and Teva; and received honoraria for presenting from Desitin, Boehringer Ingelheim, GlaxoSmithKline, Mundipharma, Novartis, Orion Pharma, Schwarz Pharma Neuroscience/UCB, and Teva. He has received scientific grants from German Ministry of Education and Health, IPF, and the Michael J. Fox Foundation, and holds shares in Roche. C. Trenkwalder has received consulting fees from Mundipharma, UCB Pharma, Desitin, Britannia, Novartis, and Orion Pharma and research funding from Mundipharma, Teva, and the Michael J. Fox Foundation. Go to Neurology.org for full disclosures.

Received March 6, 2015. Accepted in final form January 28, 2016.

\section{REFERENCES}

1. Rye DB, Trotti LM. Restless legs syndrome and periodic leg movements of sleep. Neurol Clin 2012;30:1137-1166.

2. Pennestri MH, Montplaisir J, Fradette L, Lavigne G, Colombo R, Lanfranchi PA. Blood pressure changes associated with periodic leg movements during sleep in healthy subjects. Sleep Med 2013;14:555-561.

3. Siddiqui F, Strus J, Ming X, Lee IA, Chokroverty S, Walters AS. Rise of blood pressure with periodic limb movements in sleep and wakefulness. Clin Neurophysiol 2007;118:1923-1930.

4. Pennestri MH, Montplaisir J, Colombo R, Lavigne G, Lanfranchi PA. Nocturnal blood pressure changes in patients with restless legs syndrome. Neurology 2007;68: 1213-1218.

5. Gosselin N, Lanfranchi P, Michaud M, et al. Age and gender effects on heart rate activation associated with periodic leg movements in patients with restless legs syndrome. Clin Neurophysiol 2003;114:2188-2195.

6. Hening WA, Allen RP, Ondo WG, et al. Rotigotine improves restless legs syndrome: a 6-month randomized, double-blind, placebo-controlled trial in the United States. Mov Disord 2010;25:1675-1683.

7. Trenkwalder C, Benes $\mathrm{H}$, Poewe W, et al. Efficacy of rotigotine for treatment of moderate-to-severe restless legs syndrome: a randomised, double-blind, placebo-controlled trial. Lancet Neurol 2008;7:595-604.

8. Stiasny-Kolster K, Kohnen R, Schollmayer E, Moller JC, Oertel WH. Patch application of the dopamine agonist rotigotine to patients with moderate to advanced stages of restless legs syndrome: a double-blind, placebo-controlled pilot study. Mov Disord 2004;19:1432-1438.

9. Oertel WH, Benes H, Garcia-Borreguero D, et al. Rotigotine transdermal patch in moderate to severe idiopathic restless legs syndrome: a randomized, placebo-controlled polysomnographic study. Sleep Med 2010;11:848-856.

10. Benes H, Kohnen R. Validation of an algorithm for the diagnosis of restless legs syndrome: the restless legs syndrome diagnostic index (RLS-DI). Sleep Med 2009;10: $515-523$.

11. Walters AS, LeBrocq C, Dhar A, et al. Validation of the International Restless Legs Syndrome Study Group rating scale for restless legs syndrome. Sleep Med 2003; 4:121-132.

12. National Institute of Mental Health. Clinical Global Impressions (028 CGI). In: Guy W, ed. ECDEU Assessment Manual for Psychopharmacology. Rockville, MD: National Institute of Mental Health; 1976:218-222.

13. Kemp B, Varri A, Rosa AC, Nielsen KD, Gade J. A simple format for exchange of digitized polygraphic recordings. Electroencephalogr Clin Neurophysiol 1992;82:391-393.

14. Iber C, Ancoli-Israel S, Chesson A, Quan SF, for the American Academy of Sleep Medicine. The AASM Manual for the Scoring of Sleep and Associated Events: Rules, Terminology and Technical Specifications. Westchester: American Academy of Sleep Medicine; 2007.

15. Zucconi M, Ferri R, Allen R, et al. The official World Association of Sleep Medicine (WASM) standards for recording and scoring periodic leg movements in sleep (PLMS) and wakefulness (PLMW) developed in 
collaboration with a task force from the International Restless Legs Syndrome Study Group (IRLSSG). Sleep Med 2006;7:175-183.

16. Cassel W, Kesper K, Bauer A, et al. Significant association between systolic and diastolic blood pressure elevations and periodic limb movements in patients with idiopathic restless legs syndrome. Sleep Med 2016;17:109-120.

17. Kohnen R, Benes H, Heinrich C, Kurella B. Development of the disease-specific restless legs syndrome quality of life (RLS-QoL) questionnaire. Mov Disord 2002;17(suppl 5): A232.

18. Kohnen R, Martinez-Martin P, Benes H, et al. Rating of daytime and night-time symptoms in RLS: validation of the RLS-6 scale of restless legs syndrome/Willis-Ekbom disease. Sleep Med (in press 2016).

19. Höcht C. Blood pressure variability: prognostic value and therapeutic implications. ISRN Hypertens 2013; 2013:1-16; doi: 10.5402/2013/398485.

20. Parati G, Pomidossi G, Albini F, Malaspina D, Mancia G. Relationship of 24-hour blood pressure mean and variability to severity of target-organ damage in hypertension. J Hypertens 1987;5:93-98.

21. Wei FF, Li Y, Zhang L, et al. Beat-to-beat, reading-toreading, and day-to-day blood pressure variability in relation to organ damage in untreated Chinese. Hypertension 2014;63:790-796.

22. Erden EC, Erden I, Turker Y, Sivri N, Dikici S, Ozsahin M. Incremental effects of restless legs syndrome on nocturnal blood pressure in hypertensive patients and normotensive individuals. Blood Press Monit 2012;17: 231-234

23. Espinar-Sierra J, Vela-Bueno A, Luque-Otero M. Periodic leg movements in sleep in essential hypertension. Psychiatry Clin Neurosci 1997;51:103-107.

24. Billars L, Hicks A, Bliwise D, et al. Hypertension risk and PLMS in restless legs syndrome. Sleep 2007;30: A297-A298.

25. Szentkiralyi A, Volzke H, Hoffmann W, Happe S, Berger K. A time sequence analysis of the relationship between cardiovascular risk factors, vascular diseases and restless legs syndrome in the general population. J Sleep Res 2013;22:434-442.

26. Li Y, Walters AS, Chiuve SE, Rimm EB, Winkelman JW, Gao X. Prospective study of restless legs syndrome and coronary heart disease among women. Circulation 2012; 126:1689-1694.

27. Zeng C, Zhang M, Asico LD, Eisner GM, Jose PA. The dopaminergic system in hypertension. Clin Sci 2007;112: 583-597.

28. Johns DW, Ayers CR, Carey RM. The dopamine agonist bromocriptine induces hypotension by venous and arteriolar dilation. J Cardiovasc Pharmacol 1984;6:582-587.

29. Manconi M, Ferri R, Zucconi M, et al. Dissociation of periodic leg movements from arousals in restless legs syndrome. Ann Neurol 2012;71:834-844.

30. Manconi M, Ferri R, Zucconi M, et al. Effects of acute dopamine-agonist treatment in restless legs syndrome on heart rate variability during sleep. Sleep Med 2011;12:47-55.

\section{Subspecialty Alerts by E-mail!}

Customize your online journal experience by signing up for e-mail alerts related to your subspecialty or area of interest. Access this free service by visiting Neurology.org/site/subscriptions/etoc.xhtml or click on the "E-mail Alerts" link on the home page. An extensive list of subspecialties, methods, and study design choices will be available for you to choose from-allowing you priority alerts to cutting-edge research in your field!

\section{Save These Dates for AAN CME Opportunities!}

Mark these dates on your calendar for exciting continuing education conferences by the American Academy of Neurology.Learn more at AAN.com/conferences.

\section{Sports Concussion Conference}

- July 8-10, 2016, Chicago, IL, at the Hilton Chicago

\section{Fall Conference}

- October 14-16, 2016, Las Vegas, NV, at the Cosmopolitan of Las Vegas 


\section{Neurology}

\section{Rotigotine's effect on PLM-associated blood pressure elevations in restless legs syndrome: An RCT \\ Axel Bauer, Werner Cassel, Heike Benes, et al.}

Neurology 2016;86;1785-1793 Published Online before print April 13, 2016

DOI 10.1212/WNL.0000000000002649

\section{This information is current as of April 13, 2016}

\section{Updated Information \& Services}

Supplementary Material

\section{References}

Subspecialty Collections

Permissions \& Licensing

Reprints including high resolution figures, can be found at: http://n.neurology.org/content/86/19/1785.full

Supplementary material can be found at: http://n.neurology.org/content/suppl/2016/04/13/WNL.0000000000002 649.DC2

http://n.neurology.org/content/suppl/2016/04/13/WNL.0000000000002 649.DC1

This article cites 27 articles, 2 of which you can access for free at: http://n.neurology.org/content/86/19/1785.full\#ref-list-1

This article, along with others on similar topics, appears in the following collection(s):

Class I

http://n.neurology.org/cgi/collection/class_1

Clinical trials Randomized controlled (CONSORT agreement)

http://n.neurology.org/cgi/collection/clinical_trials_randomized_control led_consort_agreement

Restless legs syndrome

http://n.neurology.org/cgi/collection/restless_legs_syndrome

Information about reproducing this article in parts (figures,tables) or in its entirety can be found online at:

http://www.neurology.org/about/about_the_journal\#permissions

Information about ordering reprints can be found online:

http://n.neurology.org/subscribers/advertise

Neurology ${ }^{\circledR}$ is the official journal of the American Academy of Neurology. Published continuously since 1951, it is now a weekly with 48 issues per year. Copyright () 2016 American Academy of Neurology. All rights reserved. Print ISSN: 0028-3878. Online ISSN: 1526-632X.

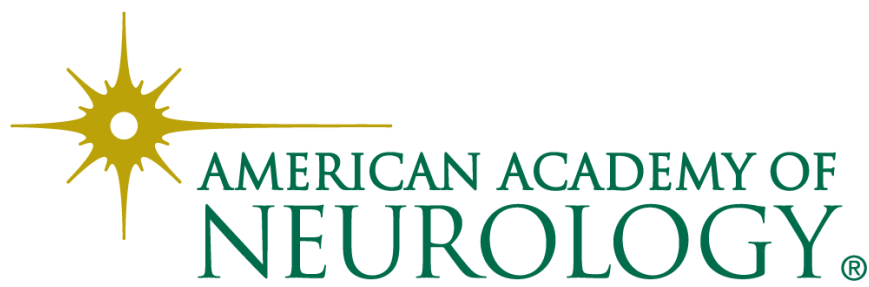

